\title{
Huge Thoracic Aortic Aneurysm Presenting with Jaundice: A Case Report
}

\author{
Othman Nasser AI Mulhim (iD) \\ Faculty of Surgery, College of Medicine, \\ King Faisal University, Al-Ahsa, Saudi \\ Arabia
}

Introduction: Thoracic aortic aneurysms (TAA) are encountered frequently in the emergency department with an obscure presentation. Most of these aneurysms are incidentally discovered while doing routine imaging studies. This report describes a case of unusual presentation of TAAs.

Case Presentation: A 37-year-old male presented to the emergency department with jaundice, shortness of breath, abdominal swelling, and lower limb edema, which worsened during the previous month. The patient was worked up and diagnosed with an ascending aortic aneurysm measuring $6.9 \mathrm{~cm}$ associated with severe aortic insufficiency and heart failure.

Conclusion: TAA is a life-threatening condition with indistinct signs and symptoms. A high index of suspicion and early implementation of radiological studies are prerequisites to reach a diagnosis.

Keywords: ascending aortic aneurysm, thoracic aortic aneurysm, clinical presentation, jaundice, transthoracic echocardiography

\section{Background}

Thoracic aortic aneurysms are often silent. ${ }^{1-4}$ Their diagnosis usually follows a pathway in which a radiological study is being performed for a different reason, and the aneurysm is discovered coincidentally. ${ }^{5}$ The etiology of aneurysmal formation is incompletely understood. ${ }^{6}$ Most aortic aneurysms are caused by degenerative, infectious, or genetic conditions that weaken the aortic wall. ${ }^{6}$ Symptomatic aortic aneurysms may manifest as chest pain, discomfort, a new cardiac murmur, or more drastically as heart failure, aortic dissection, or rupture. ${ }^{6}$ It is estimated that $21 \%$ of patients suffering from acute aortic syndromes die before reaching the

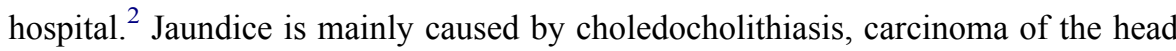
of the pancreas, biliary strictures, pancreatitis, and sclerosing cholangitis. ${ }^{7}$ Jaundice is a rare presentation of abdominal aneurysms due to obstruction to the biliary tree. ${ }^{7}$ CT or MRI confirms the diagnosis of aortic aneurysms. ${ }^{6}$ Intervention by surgery or percutaneous technology is indicated when the size of the aneurysm reaches a threshold where the risk for developing complications according to the natural history of the disease is significant. ${ }^{6,8}$

\section{Case Presentation}

A 37-year-old man who smokes but denies any previous medical illness was referred to Prince Sultan Cardiac Center complaining of worsening shortness of breath, 
especially during exertion, abdominal swelling, and lower limb edema. He has no family history of connective tissue disorders. Upon examination, the patient looked tired, jaundiced, and unable to lie flat on the bed. The patient was afebrile. His heart rate was 113 beats per minute, his blood pressure was $101 / 70 \mathrm{mmHg}$, and he saturated $97 \%$ on room air. On chest auscultation, there was an audible diastolic murmur all over the chest. The abdominal exam was unremarkable, and there was bilateral pitting edema up to the shaft of the leg. Laboratory investigations showed the following: hemoglobin of $13 \mathrm{~g} / \mathrm{dl}$, normal platelet count, elevated liver enzymes with AST of $843 \mathrm{U} / \mathrm{L}$ (Normal: 0-32 U/ L), ALT $1766 \mathrm{U} / \mathrm{L}$ (Normal 0-41 U/L), total bilirubin of 290 umol/L (Normal: 0-21 umol/L), and direct bilirubin of 200 umol/L (Normal: 0-3.4 umol/L). Creatinine was also elevated at $120 \mathrm{umol} / \mathrm{L}$ (Normal: $62-106 \mathrm{umol} / \mathrm{L}$ ). The coagulation profile was abnormal, with INR 2.15 sec., while cardiac enzymes were within normal. The patient's chest x-ray showed an enlarged cardiac silhouette (Figure 1). The abdominal ultrasound was normal. The patient had transthoracic echocardiography (TTE), which showed severely reduced ventricular function with an ejection fraction of about $25 \%$, dilated both ventricles, a bicuspid aortic valve with severe regurgitation, dilated inferior vena cava, congested liver, and an ascending aortic aneurysm with a maximum diameter of $6.9 \mathrm{~cm}$ (Figure 2). CT scan with contrast further delineated the aneurysm and its extension

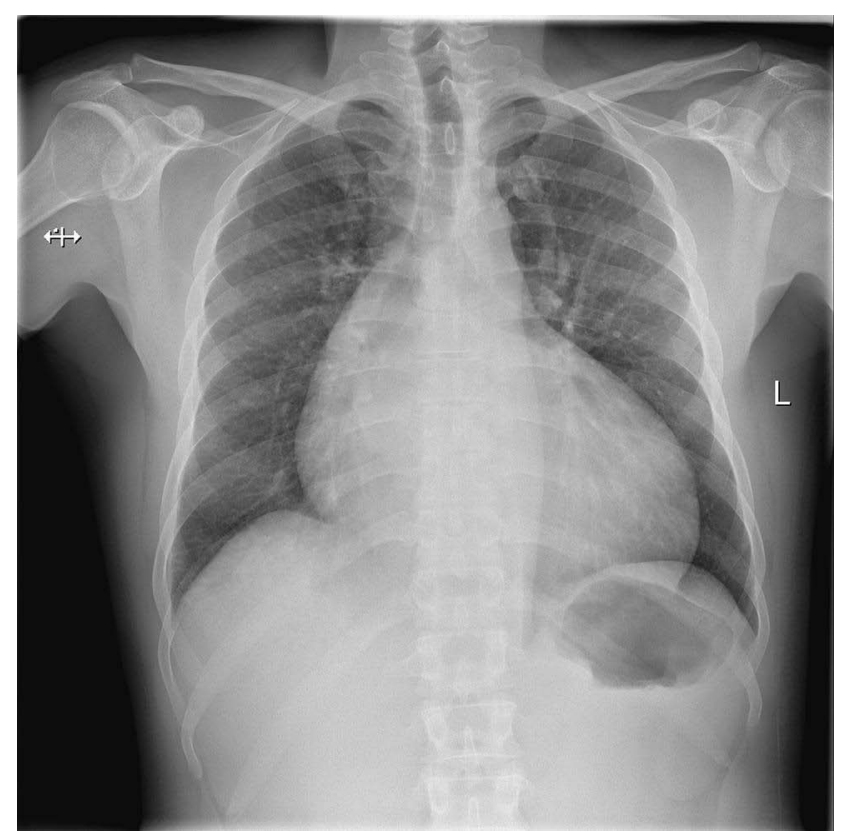

Figure I Chest X-ray showing enlarged cardiac silhouette with cardiothoracic ratio of $70 \%$, and mild pulmonary congestion.
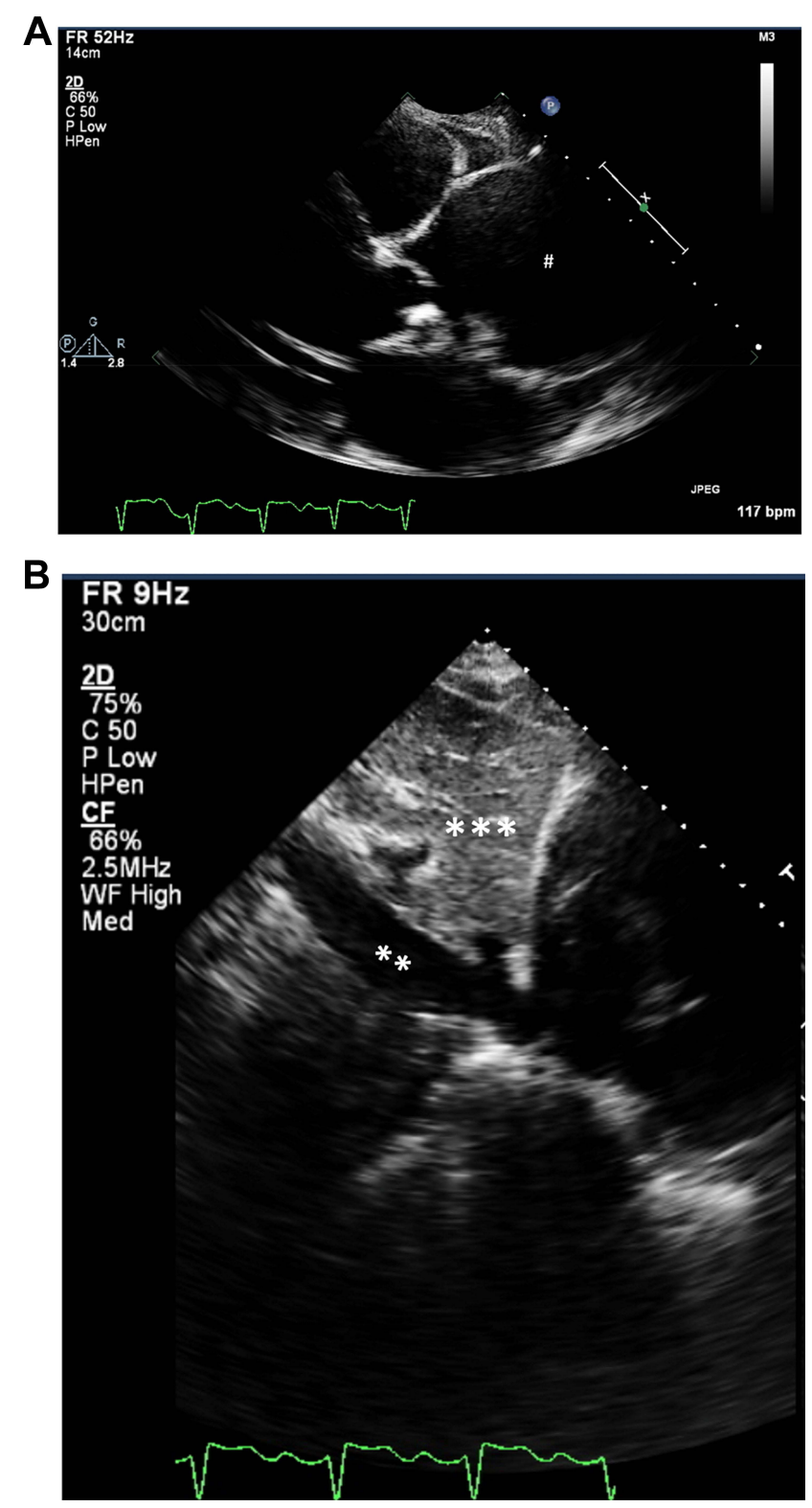

Figure 2 Transthoracic echocardiography; (A) parasternal long axis view showing an ascending aortic aneurysm (\#) and (B) subcostal view showing dilated inferior vena cava $(* *)$ and congested liver $(* * *)$.

into the distal aorta, which was only confined to the ascending aorta (Figure 3). Following an urgent heart team discussion, the patient was admitted to the intensive care unit for close observation and started on intravenous inotropes to support his circulation and optimize his condition for surgery. His blood pressure was maintained at less than 120 $\mathrm{mmHg}$, and his heart rate was sustained to 55 beats per minute. The patient underwent a modified Bentall procedure in the second week of admission. The surgery was uneventful, and the patient was discharged home one week post-surgery. Tissue pathology showed degenerative changes only. The follow-up echo four weeks later 


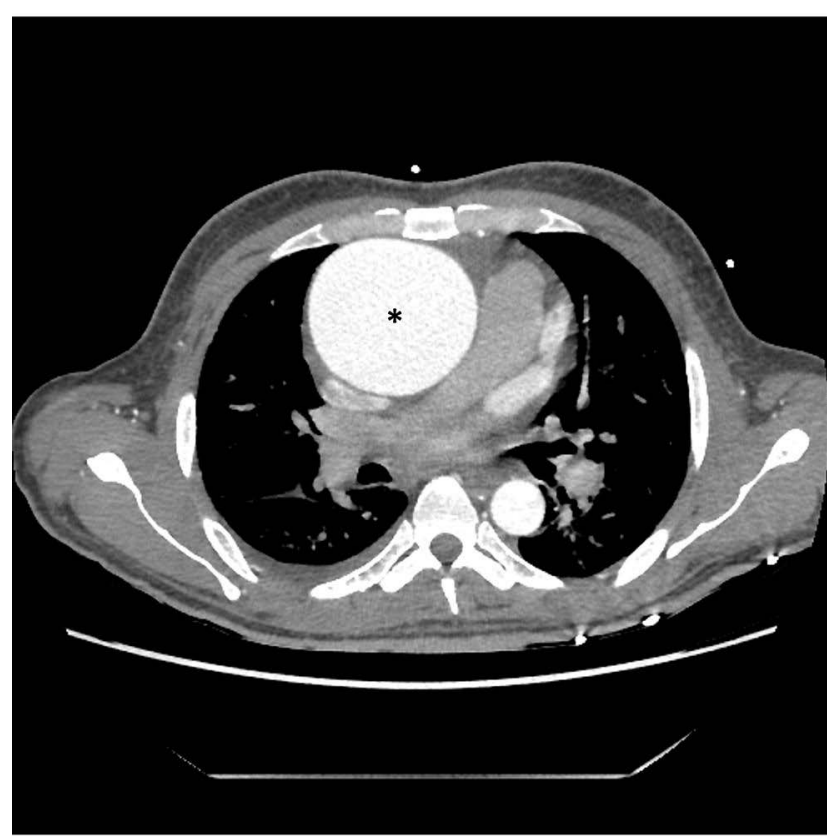

Figure 3 CT chest axial view showing a huge ascending aortic aneurysm (*).

demonstrated improvement in overall cardiac function, and the patient reported significant symptomatic improvement.

\section{Discussion}

An aneurysm can generally be defined as the enlargement of a blood vessel to more than $150 \%$ of the diameter expected for gender, age, and weight. ${ }^{4}$ Although the true prevalence of TAAs is unknown, it is estimated to have an incidence of at least 5-10 per 100,000 person-years. ${ }^{5,9}$ More than half of these aneurysms are in the ascending aorta followed in frequency by the descending thoracic aorta. Less than $10 \%$ are confined to the aortic arch. ${ }^{5}$ Atherosclerosis along with its risk factors, connective tissue disease (eg, Marfan syndrome), and abnormalities of the aortic valve (eg, bicuspid aortic valve) are strongly associated with the development of ascending aortic aneurysms, but sporadic cases have also been reported. ${ }^{10,11}$

The majority of TAAs are asymptomatic, and identifying a patient with them represents a true challenge to health care providers. ${ }^{4,5}$ TAA can be encountered during a routine radiological examination, as an acute presentation with dissection, as a part of screening the relative of a patient with a known aneurysm, or as a part of a known congenital cardiac defect. ${ }^{1}$ Frequently reported symptoms of thoracic aortic aneurysm include dyspnea, cough, dysphagia, hoarseness of voice, claudication, cerebrovascular events, as well as chest, abdominal, or back pain. ${ }^{11}$ Other unusual presentations of thoracic aneurysms reported in the literature include erosion of the overlying skin and sternum, rupture into the esophagus, compression and invasion of the pulmonary artery, superior vena cava syndrome, and recurrent laryngeal and phrenic nerve palsy. ${ }^{12-15,17,18}$ The most common causes of jaundice are choledocholithiasis, biliary strictures, carcinoma of the head of the pancreas, pancreatitis, and sclerosing cholangitis. ${ }^{7}$ Jaundice has been reported in the literature as a rare presentation of abdominal aortic aneurysm (not TAAs) because of compression and obstruction of biliary ducts. ${ }^{16}$ Right ventricular failure may precipitate liver congestion, while congestion reduces hepatic blood flow, decreases arterial oxygen saturation, and increases hepatic venous pressure. ${ }^{19}$ Laboratory abnormalities include elevated serum aminotransferase level to two to three times the upper limit of normal and hyperbilirubinemia. ${ }^{19}$ In our case, the patient developed biventricular failure, which resulted in hepatic congestion, and consequently, jaundice.

Unrecognized aneurysms risk rupture and dissection, which carry higher morbidity and mortality burden. ${ }^{18}$ To diagnose these aneurysms, the clinical history should be focused on the symptoms, risk factors, family history, and followed by detailed physical examination looking for signs of aneurysmal dilatation or its complications. ${ }^{11}$ Aortic imaging with echocardiography, computed tomography angiography, and magnetic resonance angiography remain the cornerstone to diagnose aortic aneurysms. ${ }^{11}$ Screening with transesophageal echocardiography is reasonable to evaluate the aorta in predisposed populations (eg, connective tissue disorders, bicuspid aortic valve, or screening first-degree relatives of patients with TAA). There is no recommendation for screening the general population. ${ }^{5}$ Blood pressure control is the cornerstone of nonsurgical management of small uncomplicated aneurysms. ${ }^{18}$ The significant determinants for intervention are the size of the aneurysm, rate of expansion, and associated conditions. ${ }^{11}$ Aneurysms are repaired when the risk of rupture exceeds the risk of repair. $^{5}$

\section{Conclusion}

The presentation of TAAs can be obscured. Focused clinical history, physical examination, and early implementation of diagnostic imaging aid in early recognition and management of aneurysms and avoid significant morbidity and mortality. 


\section{Abbreviations}

TAA, thoracic aortic aneurysm; CT, computed tomography; MRI, magnetic resonance imaging; AST, aspartate aminotransferase; ALT, alanine aminotransferase; TTE, transthoracic echocardiography.

\section{Ethics Approval and Consent}

Approved by the institutional review board at King Faisal University. The patient provided written informed consent for the case report to be published.

\section{Funding}

There is no funding to report.

\section{Disclosure}

The author reports no conflicts of interest in this work.

\section{References}

1. Clift PF, Cervi E. A review of thoracic aortic aneurysm disease. Echo Res Pract. 2019;7(1):R1-R10. doi:10.1530/ERP-19-0049

2. Saeyeldin AA, Velasquez CA, Mahmood SUB, et al. Thoracic aortic aneurysm: unlocking the "silent killer" secrets. Gen Thorac Cardiovasc Surg. 2019;67(1):1-11. doi:10.1007/s11748-017-0874-x

3. Elefteriades JA, Farkas EA. Thoracic aortic aneurysm clinically pertinent controversies and uncertainties. J Am Coll Cardiol. 2010;55 (9):841-857. doi:10.1016/j.jacc.2009.08.084

4. Lavall D, Schäfers HJ, Böhm M, Laufs U. Aneurysms of the ascending aorta. Dtsch Arztebl Int. 2012;109(13):227-233. doi:10.3238/ arztebl.2012.0227

5. Dudzinski DM, Isselbacher EM. Diagnosis and Management of Thoracic Aortic Disease. Curr Cardiol Rep. 2015;17(12):106. doi:10.1007/s11886-015-0655-z

6. Hiratzka LF, Bakris GL, Beckman JA, et al. 2010 ACCF/AHA/AATS/ ACR/ASA/SCA/SCAI/SIR/STS/SVM guidelines for the diagnosis and management of patients with Thoracic Aortic Disease: a report of the American College of Cardiology Foundation/American Heart Association Task Force on Practice Guidelines, American Association for Thoracic Surgery, American College of Radiology, American Stroke Association, Society of Cardiovascular Anesthesiologists, Society for Cardiovascular Angiography and Interventions, Society of Interventional Radiology, Society of Thoracic Surgeons, and Society for Vascular Medicine. Circulation. 2010;121(13):e266-e369. doi:10.1161/CIR.0b013e3181d4739e
7. Rieß HC, Tsilimparis N, Behrendt CA, Wipper S, Debus ES, LarenaAvellaneda A. Jaundice as a Rare Indication for Aortic Aneurysm Repair. Ann Vasc Surg. 2015;29(7):1454.e1-1454.e14543. doi:10.10 16/j.avsg.2015.04.080

8. Calero A, Illig KA. Overview of aortic aneurysm management in the endovascular era. Semin Vasc Surg. 2016;29(1-2):3-17. doi:10.1053/ j.semvascsurg.2016.07.003

9. Mathur A, Mohan V, Ameta D, Gaurav B, Haranahalli P. Aortic aneurysm. J Transl Int Med. 2016;4(1):35-41. doi:10.1515/jtim2016-0008

10. Alhabdan MS, AlSehly AA. Ascending aortic aneurysm. Pediatr Cardiol. 2011;32(8):1266-1268. doi:10.1007/s00246-0110103-9

11. Wang TKM, Desai MY. Thoracic aortic aneurysm: optimal surveillance and treatment. Cleve Clin J Med. 2020;87(9):557-568. doi:10.3949/ccjm.87a.19140-1

12. Ambepitiya SG, Michiue T, Bessho Y, Kamikodai Y, Ishikawa T, Maeda H. An unusual presentation of thoracic aortic aneurysm rupturing into the esophagus: an autopsy case report. Forensic Sci Med Pathol. 2010;6(2):121-126. doi:10.1007/s12024-0099137-1

13. Felix AS, Alves LA, Felipe AR, et al. Pulmonary Artery Compression and Invasion by a Ruptured Giant Thoracic Aortic Aneurysm: a Rare Presentation. CASE. 2018;2(5):201-206. doi:10.1016/j.case.2018.02.005

14. Sarangi PK, Hui P, Sagar HS, Kisku DK, Mohanty J. Combined Left Recurrent Laryngeal Nerve and Phrenic Nerve Palsy: a Rare Presentation of Thoracic Aortic Aneurysm. $J$ Clin Diagn Res. 2017;11(5):TD01-TD02. doi:10.7860/JCDR/2017/ 25035.9765

15. Bicer M, Yuksel A, Kan II. The Largest Reported Giant Ascending Aortic Aneurysm Presented with Superior Vena Cava Syndrome. Braz J Cardiovasc Surg. 2020;35(5):834-837. doi:10.21470/16789741-2019-0151

16. Changal KH, Lim F, Sunkara T, Hamdani SU. Unusual presentation of silently growing abdominal aortic aneurysm causing biliary obstruction. BMJ Case Rep. 2017;2017:bcr2017220539. doi:10.11 36/bcr-2017-220539

17. Porapakkham P. Impending rupture of aortic aneurysm eroding skin and sternum: a rare condition. Asian Cardiovasc Thorac Ann. 2019;27(4):307-309. doi:10.1177/0218492319833280

18. Booher AM, Eagle KA. Diagnosis and management issues in thoracic aortic aneurysm. Am Heart J. 2011;162(1):38-46. e1. doi:10.1016/j. ahj.2011.04.010

19. Hilscher M, Sanchez W. Congestive hepatopathy. Clin Liver Dis. 2016;8(3):68-71. doi:10.1002/cld.573
Vascular Health and Risk Management

\section{Publish your work in this journal}

Vascular Health and Risk Management is an international, peerreviewed journal of therapeutics and risk management, focusing on concise rapid reporting of clinical studies on the processes involved in the maintenance of vascular health; the monitoring, prevention and treatment of vascular disease and its sequelae; and the involvement of metabolic disorders, particularly diabetes. This journal is indexed on PubMed Central and MedLine. The manuscript management system is completely online and includes a very quick and fair peerreview system, which is all easy to use. Visit http://www.dovepress. com/testimonials.php to read real quotes from published authors. 